
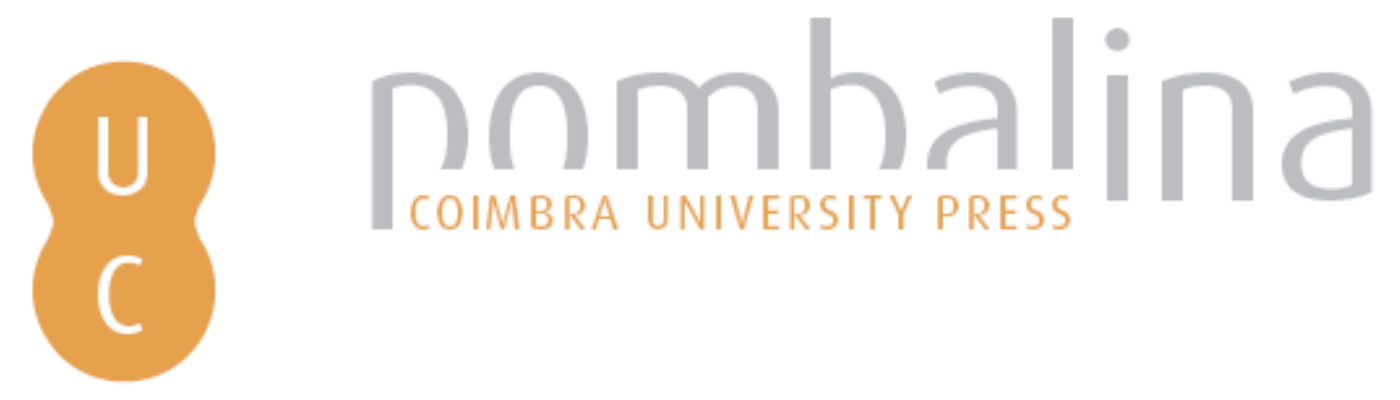

\title{
Políticas públicas para o desenvolvimento do cadastro multifinalitário rural no Brasil
}

Autor(es): $\quad$ Pelegrina, Marcos Aurélio; Julião, Rui Pedro

Publicado por: Imprensa da Universidade de Coimbra

URL

persistente:

URI:http://hdl.handle.net/10316.2/37079

DOI:

DOI:http://dx.doi.org/10.14195/978-989-26-0983-6_26

Accessed : $\quad$ 26-Apr-2023 11:21:50

A navegação consulta e descarregamento dos títulos inseridos nas Bibliotecas Digitais UC Digitalis, UC Pombalina e UC Impactum, pressupõem a aceitação plena e sem reservas dos Termos e Condições de Uso destas Bibliotecas Digitais, disponíveis em https://digitalis.uc.pt/pt-pt/termos.

Conforme exposto nos referidos Termos e Condições de Uso, o descarregamento de títulos de acesso restrito requer uma licença válida de autorização devendo o utilizador aceder ao(s) documento(s) a partir de um endereço de IP da instituição detentora da supramencionada licença.

Ao utilizador é apenas permitido o descarregamento para uso pessoal, pelo que o emprego do(s) título(s) descarregado(s) para outro fim, designadamente comercial, carece de autorização do respetivo autor ou editor da obra.

Na medida em que todas as obras da UC Digitalis se encontram protegidas pelo Código do Direito de Autor e Direitos Conexos e demais legislação aplicável, toda a cópia, parcial ou total, deste documento, nos casos em que é legalmente admitida, deverá conter ou fazer-se acompanhar por este aviso. 


\section{$\forall$ \\ TAS DAS I JORNADAS LUSÓFONAS DE CIÊNCIAS E TECNOLOGIAS DE INFORMAÇÃO GEOGRÁFICA}

Editores

José Gomes dos Santos

Cidália Fonte

Rui Ferreira de Figueiredo

Alberto Cardoso

Gil Gonçalves

José Paulo Almeida

Sara Baptista 


\begin{abstract}
ARTIGO 26
Políticas públicas para o desenvolvimento do CADASTRO MULTIFINALITÁRIO RURAL NO BRASIL
\end{abstract}

PELEGRINA, Marcos Aurélio ${ }^{1}$ E JULIÃO, Rui Pedro ${ }^{2}$

\begin{abstract}
1 Departamento de Geografia da Universidade Estadual do Centro-Oeste do Paraná (Brasil) Bolsista CAPES Processo n. BEX-9757/13-9; Departamento de Geografia, Setor de Ciências Agrárias e Ambientais - SEAA/G Rua Simeão Camargo Varela de Sá, 03 - Vila Carli | CEP 85040-080 | Guarapuava - Paraná (Brasil); Tel: +55 (42) 3629-8100 ; email: marcospelegrina@gmail.com

2 e-GEO-FCSH/UNL (Portugal); Morada: Avenida de Berna, 26-C / 1069-061 Lisboa Tel: +351 2179083 00; email: rpj@fcsh.unl.pt
\end{abstract}

\title{
RESUMO
}

No Brasil, existem basicamente dois tipos de cadastros rural e urbano. O cadastro das propriedades rurais é de responsabilidade do INCRA (Instituto Nacional de Colonização de Reforma Agrária). A publicação da Lei n ${ }^{\circ} 102672001$ melhorou muito o registro de propriedades rurais. Esta lei levou à identificação sistemática das propriedades rurais, permitindo o desenvolvimento do Cadastro Nacional de Imóveis Rurais (CNIR), e o georreferenciamento gradual das propriedades através da publicação de normas técnicas. Este artigo objetiva contextualizar políticas públicas no Brasil, com objetivo desenvolvimento do cadastro multifinalitário na área rural e demonstrar a sua importância no que tange o planejamento e o desenvolvimento territorial.

\section{PALAVRAS-CHAVE}

Cadastro multifinalitário, Sistema de informações territoriais, Gestão territorial. 
PUBLIC POLICIES TOWARDS THE DEVELOPMENT OF RURAL MULTIFUNCTIONAL PROPERTY CADASTRE IN BRASIL

\begin{abstract}
In Brazil, there are basically two types of cadastres-rural and urban. The cadastre of rural properties is the responsibility of INCRA (National Institute for Colonization of Agrarian Reform). The 2001 publication of Law No. 10267 greatly improved the registration of rural properties. This law led to the systematic identification of ruralproperties, allowing the development of the National Registry of Rural Properties (CNIR) and gradually enabling the geo-referencing of property to their technical standards. This paper aims to contextualize public policies in Brazil, with the objective development of multipurpose cadastre in rural areas and demonstrate its importance concerning planning and land development.
\end{abstract}

\title{
KEYWORDS
}

Multipurpose cadastre, Land information system, Land management.

\section{INTRODUÇÃO}

O cadastro multifinalitário pode ser definido como um sistema de informações territoriais (SIT), baseado na parcela territorial que é parte contígua da superfície terrestre com regime jurídico único. O cadastro deve ser constituído com a descrição geométrica das parcelas, em conjunto com outros registros que descrevem a natureza dos interesses da parcela, tais como: direitos, restrições e responsabilidades, bem como as condições desta propriedade ou o controle destes interesses. O cadastro multifinalitário pode ser estabelecido para finalidades fiscais (p. ex., avaliação e tributação), legais (p. ex., transferências e certidões), administrativas (p. ex., planejamento e controle do uso da terra), bem como disponibilizar informações para o desenvolvimento sustentável e a proteção ambiental, tendo como base o cadastro territorial (FIG,2006).

Um Sistema de Informações Territoriais (SIT), dever ter por base o cadastro territorial multifinalitário, composto pelo:

- cadastro físico, com a delimitação geométrica das parcelas do território;

- cadastro jurídico, onde são registrados os aspectos legais da ocupação 
do território com os devidos proprietários das parcelas territoriais;

- cadastro econômico, com os aspectos econômicos da ocupação do solo

e onde descritos os valores venais dos imóveis, utilizados para tributação imobiliária.

O Cadastro está presente nas estruturas administrativas dos Estados, independente do seu modo de produção ou regime político. O conceito de território considerado na perspectiva do cadastro é onde o governo exerce sua autoridade com objetivo de racionalizar sua completa utilização (LOCH; ERBA, 2007). O desenvolvimento territorial esta atrelado ao desenvolvimento políticas públicas para implementação do cadastro multifinalitário por parte do Estado.

Em face dessas considerações iniciais, este artigo objetiva contextualizar políticas públicas no Brasil, com objetivo desenvolvimento do cadastro multifinalitário na área rural e demonstrar a sua importância no que tange o planejamento e o desenvolvimento territorial.

\section{A EVOLUÇÃo do CADASTRO}

A declaração sobre o futuro do Cadastro denominada de Cadastro 2014 elaborada pela Federação Internacional de Geômetras - FIG - (acrônimo francês de Federação Internacional de Agrimensores), é um importante documento norteador das políticas públicas para implementação do cadastro multifinalitário. Esta declaração, elaborada pelo GT 01 (Grupo de Trabalho) da comissão 7 da FIG, composto por 40 membros e envolvendo 26 Países, originou um documento sobre o futuro do cadastro, estabelecendo metas a serem cumpridas no decorrer dos anos seguintes, ou seja, até o ano de 2014. A missão deste GT foi denominada "Visão do Cadastro 2014", a partir de estudos dos sistemas cadastrais existentes e das respostas recebidas dos questionários aplicados anualmente aos membros do GT. O primeiro questionário foi enviado em fevereiro 1995 a setenta delegados e sócios da comissão. As perguntas versavam sobre os seguintes temas (KAUFMANN, J. et al, 1998):

1. caracterização do cadastro existente; 
2. aspectos do cadastro territorial multifinaliário;

3. aspectos da privatização do cadastro;

4. tributação;

5. conflitos existentes nos sistemas cadastrais;

6. reformas cadastrais.

Foram estabelecidas seis diretrizes para o que foi denominado Cadastro 2014:

I. O cadastro deverá detalhar a situação legal do uso do solo, incluindo os direitos públicos e restrições.

II. A separação entre mapas (representação gráfica) e dados alfanuméricos deixará de existir.

III. Os mapas cadastrais (cartas topográficas, croquis, plantas de quadras, etc.) deixarão de existir, sendo substituídos por modelos de dados cadastrais que irão gerar os mapas automaticamente em qualquer contexto que for necessário: relatórios gerenciais, análises estatísticas, material para impressão, etc.

IV. A utilização de meios analógicos (caneta, papel, etc.) deixará de existir no âmbito do Cadastro, dando espaço a metodologias baseadas em recursos totalmente digitais (PDA, computadores, etc.).

V. O Cadastro contará com uma grande participação da iniciativa privada, que passará a gerir as bases cadastrais. As instituições privadas e públicas irão trabalhar integradas, esta última em posição de órgão supervisor e normatizador.

VI. Garantia de retorno de investimento. Com a participação da iniciativa privada provendo os meios para garantir a gestão territorial com segurança técnica (medições) e jurídica, um modelo lucrativo deverá ser concebido.

Resumidamente, o documento Cadastro 2014 aponta para uma tendência de evolução. Estas transformações permitirão, no futuro, que ele seja o espelho de todo o território. Não haverá separação entre os dados cartográficos e a base alfanumérica, proporcionando uma maior garantia 
jurídica e permitindo um controle maior da administração sobre uso e ocupação do solo.

Na Figura 1 apresenta-se um esquema que expõe a evolução da concepção do cadastro, proposto por Erba, 2007. A primeira etapa mostra que a evolução baseada na recuperação da receita tributária. Nesta fase, o cadastro deverá promover a equidade tributária. Para tanto, deverá lastrear-se num sistema de gestão cadastral com base em Cartografia cadastral adequada, integração entre o cadastro econômico e físico.

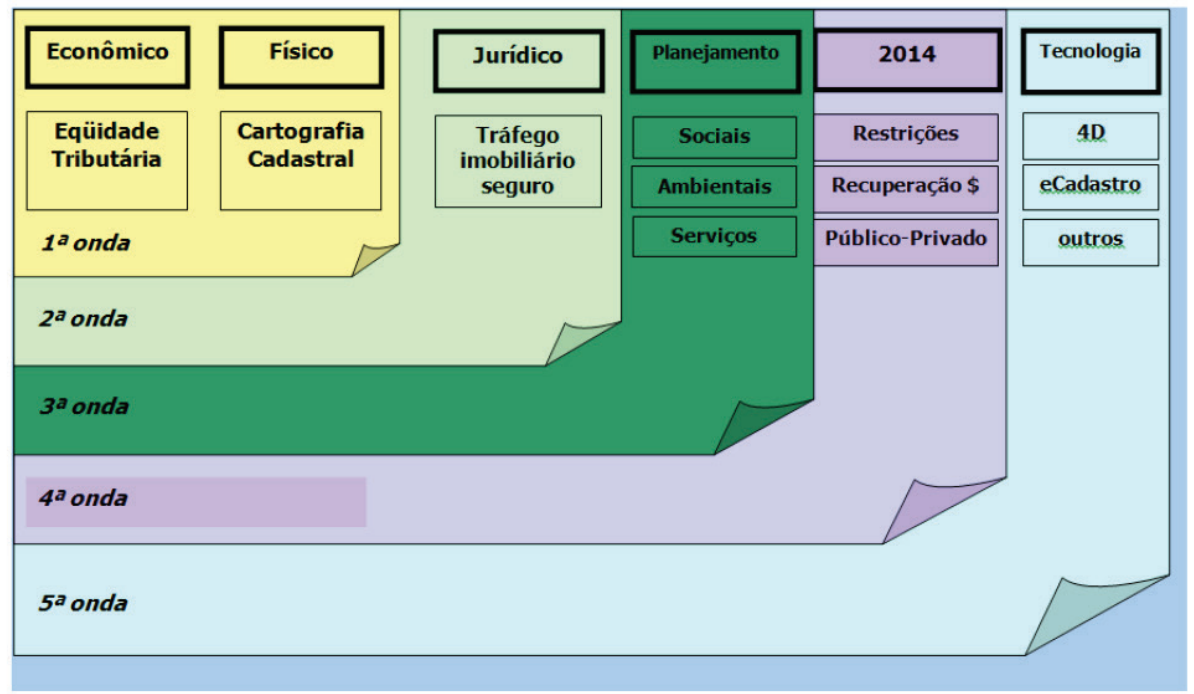

Figura 1 - Evolução do Cadastro

Fonte: Erba, 2007

Já a segunda etapa representa a integração do cadastro com o registro de imóveis (cadastro jurídico), promovendo uma garantia jurídica nas transações imobiliárias e melhor ordenamento territorial. A etapa seguinte representa a integração do cadastro com o planejamento e o ordenamento territorial, incluindo, em suas bases, o controle urbanístico, ambiental, de serviços públicos e das ações sociais.

A quarta etapa é a concretização das ações contidas na declaração da FIG Cadastro 2014.

A quinta e última fase momento em que o cadastro será beneficiado 
pelas tecnologias existentes, permitindo visualizar seus dados em 4D, ou seja, agregando a variável tempo às três dimensões existentes da cartografia. Além de permitir o acompanhamento da variação das informações ao longo do tempo, possibilitará sua disponibilização através de aplicativos da WEB.

Alguns ditames contidos no documento produzido pela FIG, bem como a diretrizes e declarações sobre o futuro do cadastro mundial são fundamentais para a evolução do pensamento cadastral no Brasil.

\section{Políticas públicas para o desenvolvimento do Cadastral MULTIFINALITÁRIO NO BRASIL}

O Brasil possui basicamente dois tipos de cadastro: um relativo à área rural e outro, à área urbana. O cadastro dos imóveis rurais é de competência do Instituto de Colonização de Reforma Agrária (INCRA), que obteve um grande avanço ao se consolidar com a promulgação da Lei n¹0.267/2001, que trata de alterações na Lei dos Registros Públicos. O cadastro urbano é de competência dos municípios, sendo de abrangência local. Mas não existe um órgão público e oficial com responsabilidade legal sobre as medições cadastrais.

$\mathrm{Na}$ área rural o cadastro esta dividido da seguinte forma: o cadastro geométrico é de responsabilidade do Instituto de Colonização de Reforma Agrária (INCRA); o Cadastro Jurídico é de responsabilidade dos cartórios de registro de imóveis; o cadastro fiscal é de responsabilidade da Receita Federal órgão público federal responsável pela tributação; e o cadastro ambiental é de responsabilidade do Ministério do Meio Ambiente através do Instituto Brasileiro do Meio Ambiente e dos Recursos Naturais Renováveis (IBAMA).

O cadastro dos imóveis rurais obteve um grande avanço através do marco legal da alteração da Lei dos Registros Públicos e a publicações de normas técnicas para execução do levantamento cadastral. Essa mudança jurídica alterou a sistemática relacionada à identificação dos imóveis rurais, permitindo o desenvolvimento do Cadastro Nacional de Imóveis Rurais (CNIR) e obrigando gradativamente ao georrefereciamento dos imóveis 
de acordo com as normas técnicas definas pelo INCRA. Tal metodologia obriga apresentação de planta e memorial descritivo do imóvel com a precisão posicional dos vértices definidores dos limites do imóvel rural $(0,50 \mathrm{~m})$. Também preconiza a troca de informações entre o INCRA responsável pelo cadastro geométrico e o registro imobiliário responsável pelo cadastro jurídico e a receita federal responsável pela tributação.

A grande inovação tecnológica aconteceu em 2013 com à implementação do SIGEF (Sistema de Gestão Fundiária), que é um portal na Internet que permite o acesso público de todas as informações territoriais rurais certificadas pelo INCRA. Através deste sistema os profissionais de cadastro habilitados pelo CREA (Conselho Federal de Engenharia, Agronomia e Geociências) e pelo INCRA, inserem seus trabalhos de levantamento cadastral. O sistema funciona através de certificação digital conforme os padrões da Infraestrutura de Chaves Públicas (ICP-Brasil).

As informações cadastrais são recebidas através de uma padronização de dados e sua validação é automatizada, verificando todas as inconsistências de dados conforme as normas técnicas. Não havendo nenhuma irregularidade é gerado um termo de responsabilidade pelas informações inseridas no sistema, em seguida é emitido o certificado do imóvel. Depois desse processo o sistema permite a impressão da planta do memorial descritivo e da certificação, que serão utilizados pelo profissional para retificação do imóvel no registro de imóvel. Existe a possibilidade de inclusão de novas informações do registro de imóveis (matrícula e proprietário) via internet, permitindo a efetiva sincronização entre os dados do cadastro geométrico e o cadastro jurídico.

O registrador responsável pelo cadastro jurídico compete verificar veracidade das informações territoriais presentes na certificação do imóvel, informando seu parecer positivo ou negativo no próprio SIGEF. Havendo alguma falha por parte do profissional de cadastro este será notificado pelo INCRA e devera responder sobre o seu levantamento cadastral.

Na Figura 2, apresenta os imóveis certificados pelo INCRA publicados pelo SIGEF. O acesso foi efetuado através do ARCGIS, em 3 de fevereiro de 2014, via geoserviço WMS (Web Map Service) no seguinte endereço eletrônico: htp://acervofundiario.incra.gov.br/i3geo/ogc.php?tema=d:/ 
ms4w/tmp/ms_tmp/hdhazW Otwt/hdhazWOtwt.map\&.

Segundo o site Mundogeo (2014), já foram certificados pelo sistema SIGEF 75,4 mil imóveis rurais em todo o País em universo de 5.204.130 imóveis. A área total de imóveis certificados é de 151,1 milhões de hectares no universo de 354.865.534 hectares (IBGE,2006). O mesmo site informa que INCRA firmou acordos de cooperação com vários órgãos públicos para acesso às bases de dados de imóveis rurais. Dentre os parceiros estão Banco do Brasil, Receita Federal, Tribunal de Contas da União, Banco Central, Polícia Federal, ministérios da Agricultura, Pecuária e Abastecimento, do Trabalho e Emprego, Ministério Público Federal, além de 2.630 municípios.

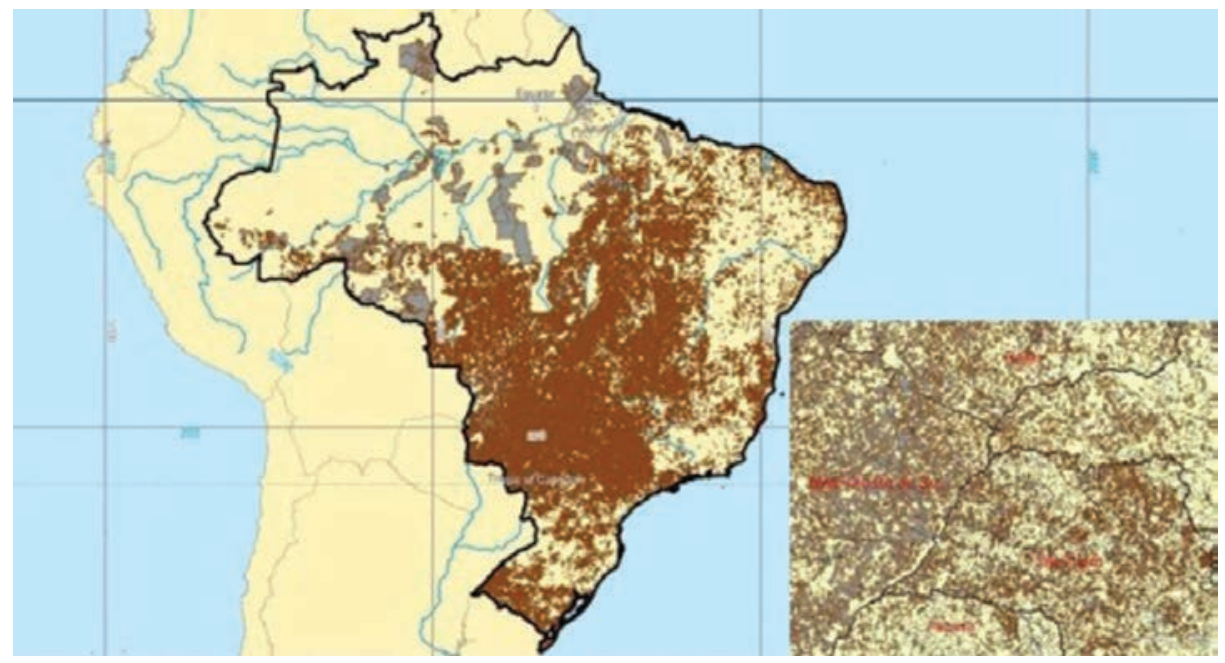

Figura 2 - Imóveis certificados pelo INCRA Fonte: INCRA (2014)

O cadastro fiscal é gerenciado pela Receita Federal que é responsável pela gestão do Imposto Territorial Rural (ITR) que é um imposto federal que é arrecadado através de uma declaração do contribuinte eletronicamente. Ao contrário do imposto territorial nas áreas urbanas em que é de responsabilidade dos municípios o cálculo e seu lançamento. Já no ITR cabe ao proprietário rural lançar o valor de sua propriedade. As informações cadastrais declaradas são: o valor da terra e o grau de produtividade 
das mesmas. Com essas informações territoriais é calculado o valor do imposto devido. Sem fiscalização o proprietário declara um valor muito abaixo do mercado. O imposto continua sendo federal, de competência da União, pois a cobrança e todo o processo continuam sendo feito pela própria Receita Federal, uma vez que a responsabilidade do município se restringe unicamente à fiscalização dos valores declarados.

No ano de 2005 após reivindicação das entidades que representam os municípios foram publicas a Lei $\mathrm{n}^{\circ} 11.250$, de 27 de dezembro de 2005 e o Decreto $n^{\circ}$ 6.433, de 15 de abril de 2008. Ambos permitem os municípios assumirem a fiscalização e cobrança do ITR, por meio de convênio com a Receita Federal. Caberá ao município a atualização dos dados que definem o VTN (Valor da Terra Nua) - principal fator da base do cálculo do imposto.

O Cadastro Ambiental Rural foi implementado com a Lei $\mathrm{n}^{\circ}$ 12.651/2012 que dispõe sobre a proteção da vegetação nativa, revoga o Código Florestal (Lei 4.771/1965), no âmbito do Sistema Nacional de Informação sobre Meio Ambiente - SINIMA, que é registro público eletrônico de âmbito nacional, obrigatório para todos os imóveis rurais, com a finalidade de integrar as informações ambientais das propriedades e posses rurais, compondo base de dados para controle, monitoramento, planejamento ambiental e econômico e combate ao desmatamento.

O Sistema de Cadastro Ambiental Rural - SICAR foi criado em através do Decreto $\mathrm{n}^{\circ} 7.830 / 2012$, tem como objetivos fazer toda gestão dos dados do CAR dos entes federativos; monitorar a manutenção, a recomposição, a regeneração, a compensação e a supressão da vegetação nativa nos imóveis rurais; promover o planejamento ambiental e econômico do uso do solo e a conservação ambiental no território nacional. Também é responsável por disponibilizar informações de natureza pública sobre a regularização ambiental dos imóveis rurais na Internet. O cadastro é realizado de forma declaratória de responsabilidade do proprietário do imóvel. As informações cadastrais declaradas são as seguintes: Identificação do proprietário/ posseiro, dados do imóvel, Geolocalização do imóvel, perímetro do imóvel rural, áreas de interesse social e de utilidade pública, áreas com remanescentes de vegetação nativa, APP (área de preservação ambiental) e área 
de Reserva Legal, áreas de uso restrito, áreas consolidadas.

O Cadastro Ambiental Rural (CAR), ainda não elaborou uma norma técnica para delimitação das áreas de proteção ambiental, assegurando assim que a base geométrica dos limites definidores, sejam os mesmos da Lei $\mathrm{n}^{\circ} 10.267 / 01$, para efetiva confrontações de dados geoespaciais.

\section{Conclusões}

Existem várias formas de desenvolvimento de políticas públicas para implementação do cadastro multifinalitário. Entre elas podemos citar o levantamento cadastral de forma massiva (de todo universo cadastral), como adotado pelo governo de Portugal. Ou através da adoção de marcos jurídicos e normas técnicas como adotado na área rural no Brasil.

Podemos concluir que as políticas públicas implementadas na área rural no Brasil foram eficientes do ponto de vista financeiro na sua execução. Os números apresentados referem-se ao levantamento cadastral de propriedades rurais ligadas ao agronegócio, que necessitam do cadastro para dar de garantia jurídica aos seus financiamentos bancários. Como o levantamento é realizado pelo proprietário o País economizou milhões de reais na elaboração desses cadastros. Além dessa economia para o Estado, o modelo adotado gerou empregos e movimentou economia local, já que a norma obriga que o levantamento deva ser feito por profissional habilitado com registro no INCRA. Outro ponto relevante é que as normas técnicas e o SIGEF, exigem que os levantamentos cadastrais possuam qualidade posicional e temática dos seus dados.

$\mathrm{O}$ acesso a informações cadastrais rurais mesmo parcialmente como atualmente pelo SIGEF, já permite que o Estado e a sociedade se beneficiem do cadastro multifinalitário. A recente integração das informações do INCRA com os bancos como citado nesse artigo, promove uma maior segurança jurídica no financiamento da produção agrícola no País. A integração com o registro de imóveis promoveu uma maior segurança jurídica ao mercado imobiliário rural, atraindo maiores investimentos para esse setor da economia. Na cobrança de impostos territoriais foram criadas novas formas fiscalização que no futuro promoverá uma maior 
justiça tributária.

Para um País com dimensões continentais como o Brasil, ter boa parte do seu território já cadastrado é um grande avanço para o desenvolvimento do seu território. O Estado no futuro próximo, deverá realizar o levantamento das pequenas propriedades rurais para completar o cadastro de todo o seu território.

\section{BIBLIOGRAFIA}

FIG - Federação Internacional dos Geômetras, PCGIAP-Working Group 3 "Cadastre" FIG-Commission 7 "Cadastre and Land Management". Modelo Cadastral 2003. Disponível na Internet via WWW. URL: http://www.cadastraltemplate. org/, acessado em 08.10.2006.

FIG - Federação Internacional dos Geômetras, Comissão 7. Cadastre 2014: a Vision for a Future Cadastral System. Disponível na Internet via WWW. URL: http://www.swisstopo.ch/fig-wg71/cad2014/cad2014/index.html, acessado em 04.06.2006.

KAUFMANN, J., STEUDlER, D. (1998). Cadastre 2014 - A Vision for a Future Cadastral System. Technical Session 7, XXI FIG-Congress, Brighton. July 1998.

INCRA (2007) - Acervo fundiário Geoserviço WMS (Web Map Service). Disponível : http://acervofundiario.incra.gov.br/i3geo/ogc.php?tema=d:/ms4w/tmp/ ms_tmp/hdhaz WOtwt/hdhazWOtwt.map\&. Acesso dia (03/02/2014). Loch, Carlos ; Erba, Diego Alfonso. Cadastro técnico multifinalitário : rural e urbano. - Cambridge, MA: Lincoln Institute of Land Policy. 142p. : il.

Ministério do Planejamento, Orçamento e Gestão Instituto Brasileiro de Geografia e Estatística - IBGE CENSO AGROPECUÁRIO 2006 resultados preliminares. ISSN 0103-6157 Censo agropec., Rio de Janeiro, p.1-146, 2006.

Mundogeo - Incra Cumpre Meta. Disponível: http://mundogeo.com/blog/2014/02/03/ incra-cumpre-metas-e-inicia-2014-com-nova-perspectiva-de-atuacao/. Acesso dia $(04 / 02 / 2014)$. 
Série Documentos

Imprensa da Universidade de Coimbra

Coimbra University Press

2015

- U M

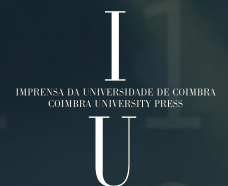

